\title{
ОБ ЭФФЕКТИВНОСТИ ОРГАНИЗАЦИОННЫХ ФОРМ ВЗАИМОДЕЙСТВИЯ СЛЕДОВАТЕЛЯ С ОРГАНАМИ ДОЗНАНИЯ
}

\section{ABOUT EFFECTIVE ORGANIZATIONAL FORMS OF INTERACTION BETWEEN INVESTIGATORS AND AGENCIES OF INQUIRY}

\section{Aristarkhov}

Summary. The article outlines the topical problems of communication between the investigator and the inquiry bodies in the investigation of crimes in real nowadays conditions. It is in ensuring the communication and interaction of the subjects of the investigation that the necessary condition for an effective investigation has been found. It is the effective interaction in law enforcement agencies that can make it possible to solve an important task of the preliminary investigation. The procedural essence of the investigator's activities is manifested through the legal endowment of the investigator with the appropriate powers to investigate and solve crimes. With an effective investigation of crimes, along with procedural, an organizational form of interaction is carried out. The lack of interaction, including its elementary form - communication between the services of the carrying out operational-search bodies activities and investigating authorities on the circumstances of the criminal case leads to ineffectiveness of the criminal proceedings of the law enforcement agencies, as a logical result of the investigation and disclosure of the crime timely and effective investigation of many crimes involves a combination of procedural and organizational activities, which is possible only with effective interaction between the subjects of law enforcement.

Keywords: interaction, bodies of inquiry, investigator, organizational forms of interaction, crime, fight.
Аристархов Дмитрий Анатольевич Аспирант, ФГБОУ ВО «Башкирский государственный университет», г. Уфа

Dimaris90@mail.ru

Аннотация. В статье обозначаются актуальные проблемы взаимодействия следователя с органами дознания при расследовании преступлений в современных условиях. На данный момент одной из важных нерешенных задач предварительного следствия по раскрытию преступлений обуславливается недостаточной эффективностью и низким уровнем организованности совместной работы субъектов, расследующих дело, с другими правоохранительными органами-участниками. В раскрытии преступлений с помощью передачи следователю соответствующих полномочий определяется его процессуальная сущность деятельности. Отсутствие взаимодействия, в том числе его элементарной формы — коммуникации между службами органа дознания и следствия по обстоятельствам уголовного дела приводят к неэффективности производства по уголовному делу правоохранительных органов, как логичному итогу работы по расследованию и раскрытию преступления. Умелое сочетание процессуальной и организационной деятельности и эффективное взаимодействие может являться залогом результативного расследования преступлений.

Ключевые слова: взаимодействие, органы дознания, следователь, организационные формы взаимодействия, преступность, борьба.

всевозможные стати реализации [1-4]. Главным регулирующим документом и правовой основой для осуществления процессуальной формы взаимодействия установлен и должен быть использован уголовно-процессуальный кодекс РФ.[5].

Процессуальная форма взаимодействия может быть рассмотрена на примере деятельности следователей, проводящих расследования в рамках следственной группы. Уголовно-процессуальный кодекс фиксирует следующие возможности: в раскрытии преступлений с помощью передачи следователю соответствующих полномочий определяется его процессуальная сущность деятельности. Таким образом, следователь полномочен направлять в органы дознания обязательные 
к исполнению поручения. Помимо письменных заданий и поручений, следователь правомочен требовать выполнения мероприятий оперативно-розыскного характера и иных процессуальных действий (арест, задержание, производство и т.д.).

Формирование следственно-оперативных групп, а также привлечение к ней сотрудников, осуществляющих оперативно-розыскную деятельность в установленном порядке должны быть использованы в целях организации качественного расследования и достаточного объема процессуальных действий.

Помимо процессуальной формы взаимодействия необходимо учитывать и использовать организационную. Для нее регулирующими и регламентирующими основами ведомственные и межведомственные нормативно-правовые акты [6-9].

Выделим основные элементы деятельности, которые целесообразно, по нашему мнению, отнести к ряду организационных форм:

- проведение оперативно-розыскных мероприятий в совместном формате;

- своевременный обмен актуальными данными среди участников следственно-оперативных групп;

- ознакомление со сведениями, выясненными оперативно-розыскным путем.

В ходе исследования, авторами Ларичев В.Д. и Кучкина В.Г. было проведено анкетирование, которое показало следственно-оперативную группу как высоко результативную форму организации взаимодействия. Данное анкетирование было проведено среди сотрудников правоохранительных органов и выявило прямое положительное влияние использования данной организационной формы на уровень раскрытия и расследования преступлений [10-12]. Были рассмотрены следующие характеристики как преимущественные:

- составление общего (совместного) плана расследования

- рассредоточение обязанностей между участниками группы и координация выполнения обязательств

- ускоренный процесс принятия организационных решений

- комплексное совмещение сил участников группы

- контроль за своевременностью, содержанием и результативностью деятельности всех принимающих участие в расследовании

- создание комфортных условий для осуществления следственных, оперативных, и иных действий.
Все вышеперечисленные факторы служат весомыми преимуществами к формированию следственно-оперативных групп.

В связи с показателями исследований многочисленных авторов полагаем, что при организации работы правоохранительных органов должен быть принят к сведению следующий факт, что следственно-оперативным группам должно быть отведено особое место. Больше всего - по сложным и неочевидным преступлениям. К тому же, по таким преступлениям в целях максимального быстрого определения всех обстоятельств дела, розыска подозреваемых лиц по «горячим следам» следственно-оперативные группы нужно создавать на этапе возбуждения уголовного дела. Такое решение может предотвратить задержки в расследовании и утерю ключевых фактов в ходе расследования. Следует заметить, что на практике по большей части случаев воспроизводится совершенно иная ситуация. Таким образом, по уголовному делу № 12001800060000708 , возбужденному по факту дистанционного хищения неустановленными лицами денежных средств в особо крупном размере с расчетного счета коммерческой организации следственно-оперативная группа не только не была создана, но и на протяжении всего срока предварительного следствия не было выполнено ни одного следственного действия. Все расследование по такому сложному и нестандартному преступлению свелось лишь к возбуждению уголовного дела, последующему продлению срока предварительного следствия и логичному в такой ситуации приостановлению предварительного следствия в связи с не установлением лица, подлежащего привлечению в качестве обвиняемого. Службы органа дознания, которые были задействованы в раскрытии преступления, такие как уголовный розыск, экспертно-криминалистический центр, а также иные подразделения действовали при данных обстоятельствах разрозненно, преследуя общую основную цель каждого своего подразделения - избежать ответственности в случае не раскрытия преступления и контроля вышестоящего начальства или органа. Отсутствие взаимодействия, в том числе его элементарной формы - коммуникации между службами органа дознания и следствия по обстоятельствам уголовного дела привели к неэффективности производства по уголовному делу правоохранительных органов, как логичному итогу работы по расследованию и раскрытию преступления. Все вышеназванные обстоятельства были также отягчены многочисленными передачами дела к производству от одного следователя к другому. В результате чего, преступление не только не было раскрыто, но хуже того, было потеряно драгоценное время, которое представляет невосполнимую ценность по уголовным делам такого характера и за которое можно было по «горячим следам» определить ключевые обстоятельства дела 
и изобличить виновных лиц, совершивших преступление. Вместо этого, должностная волокита, отсутствие мотивации и всевозможное избежание ответственности за свои действия в комплексе с организационной несостоятельностью руководителей правоохранительных органов и некомпетентностью рядовых исполнителей привели к полному провалу. Как отмечает А.А. Тарасов, именно благодаря поддержанию личной заинтересованности следователя в сотрудничестве с выделенными участниками можно раскрыть творческое отношение в группе. Никакой силой приказа побудить возникновение таких взаимоотношений невозможно. [00]. К вышесказанному следует добавить, что творческий процесс прежде всего обусловлен заинтересованностью субъекта(ов) расследования в раскрытии преступления. В ситуации, когда руководство правоохранительного органа не видит заинтересованности в расследовании преступления в силу отсутствии в совершенном преступлении ущерба государству, себе или своим знакомым, в комплексе с постоянной текучкой кадров среди рядовых следователей и сотрудников органов дознания из-за постоянных переработок и отсутствия должного материально-технического обеспечения на службе, все это полностью уничтожает творческий процесс в работе и не способствует результативной работе по делу.

На данный момент в регламентирующих документах уголовно-процессуального законодательства нельзя найти четкого понятия, необходимости и оснований формирования следственно-оперативных групп и порядка их создания. В уголовно-процессуальном кодексе Российской Федерации можно найти близкое, по существу, понятие следственной группы. В соответствии с ч. 1 ст. 163 УПК РФ «производство предварительного следствия по уголовному делу в случае его значительного объема или высокого уровня сложности может быть поручено следственной группе». Считаем объективным на практике правоприменения перспективу отведения основного места для следственно-оперативных групп при расследовании преступлений. В данном случае постановление руководителя следственного органа должно быть законным и достаточным основанием для формирования группы. К работе следственной группы, по определению статьи, могут быть привлечены должностные лица органов дознания. В терминологии научной литературы можно найти другие вариации обозначения следственной группы, такие как:
- группа следователей $[13,14]$;
- следственная бригада $[17,18] ;$
- бригада следователей $[15,16]$.

При обращении к терминологии, описывающей следственную группу, автора Цоколова И.А., заслуженного юриста РФ, подобрана максимально точная и подходящая формулировка: «основанное на законе вре- менное организационное формирование, созданное для расследования конкретного уголовного дела в целях быстрого и полного раскрытия и расследования преступления и состоящее из нескольких следователей, один из которых принимает дело к своему производству и руководит действиями других следователей» [22]. Следует добавить, что в соответствии с ч. 2 ст. 163 с ч. 2 ст. 163 уголовно-процессуального кодекса Российской Федерации только руководитель органа следствия полномочен принимать ключевые организационные решения. К таким решениям при формировании следственной группы можно отнести необходимость производства предварительного следствия выделенной следственной группой. Изменение состава следственной группы также должно быть в полномочиях вышеупомянутого руководителя. Нужно отдать отдельное внимание понятию и функциям следственной группы: она может быть создана уже в рамках существующего расследования по возбужденному ранее уголовному делу. Формирование же следственно-оперативной группы после возбуждения уголовного дела не имеет смысла. Во время проведения проверки по сообщению о преступлении уместно осуществить формирование следственно-оперативной группы. Нужно отметить, что ее деятельность особенно актуальна на этапе возбуждения уголовного дела. Опираясь на это, можно предположить обоснованность возбуждения уголовного дела и уголовно-процессуальных отношений.

Порядок, основания, требования к созданию следственно-оперативных групп, на наш взгляд, должны быть рассмотрены подробнее и регламентированы в соответствии с вышеописанной деятельностью. Несправедливо не согласиться с В.В. Степановым и И.П. Можевой в том, что ст. 163 уголовно-процессуального кодекса Российской Федерации не позволяет выделять обособленно понятие следственно-оперативной группы. Условия для формирования группы и привлечения к ней соответствующих лиц органов дознания не отменяют того, что в норме не содержится в принципе соответствующего термина [24]. Мы можем однозначно заявить, что для формирования следственно-оперативной группы недостаточно привлечения сотрудников органов оперативно-розыскной деятельности к работе следственной группы. Многие авторы популярных научных трудов пытались сформулировать определение следственно-оперативных групп для описания максимально приближенных условий, достаточных для формирования и регулирования деятельности таких групп. Например, автор Бажанов С.В. определил: «организационно-процессуальное формирование следователей и оперативных работников органов внутренних дел, которые под руководством следователя, принявшего дело к производству, обеспечивают совместное, согласованное по целям, месту, времени раскрытие и расследование сложных и больших по объему 
уголовных дел о наиболее тяжких преступлениях» [26]. По указанной характеристике описанная структура иерархично состоит из тесно связанных следователя и оперативных работников, находящихся у него в подчинении. В существующей следственно-оперативной практике соответствующей организации не предусмотрено, так как в следственную группу могут входить и сотрудники других правоохранительных органов помимо сотрудников органов внутренних дел. При этом на сегодняшний день для успешного расследования сложных и нетривиальных уголовных дел подобная практика все-таки применяется. К тому же, следственно-оперативные группы создаются иногда даже для решения текущих задач. К таким группам можно отнести дежурные следственно-оперативные группы [27]. По мнению И.А. Цоколова, эксперта в области уголовно-правовой квалификации преступной деятельности, следственно-оперативная группа - «это основанное на законе и ведомственных НПА временное организационное формирование, состоящее из следователя/ следователей, сотрудников оперативных служб субъектов оперативно-розыскной деятельности и иных специалистов, возглавляемое следователем и создаваемое для оптимальной организации деятельности по раскрытию и расследованию преступлений» [22]. В связи с описанной выше формулировкой напрашивается вывод о недостаточности высокого объема уголовного дела и его трудоемкости как ключевых критериев для решения о формировании следственно-оперативной группы. Наоборот, отнести к таким критериям можно нетривиальность задачи по раскрытию преступления и невозможность проведения расследования без участия на постоянной основе сотрудников выделенных оперативных подразделений. Следующие критерии можно отметить как дополнительные, однако обязательные к рассмотрению:

- вариативность, объем и количество следственных версий, подлежащих обработке;

- трудоемкость планируемых действий в рамках следствия, связанная непосредственно с количественно большим участников и многочисленными эпизодами преступной деятельности;

- значительное количество следственных действий и оперативно-розыскных мероприятий, подлежащих проведению.
В соответствии с ч. 2 ст. 163 уголовно-процессуального кодекса Российской Федерации к работе следственных групп могут быть привлечены лица органов, осуществляющих оперативно-розыскную деятельность. В настоящее время при планировании и проведении работ следователь имеет право и возможность поручать выделенные оперативно-розыскные мероприятия только через начальника органа дознания. Однако считаем уместным внести изменения для снижения временных проволочек по процессу: ввести функциональное подчинение путем внедрения в уголовно-процессуальное законодательство дополнительного права следователя. С помощью новых полномочий следователь сможет поручать это непосредственно участникам группы, и контролировать результаты работы, предоставленные ответственным за свой участок работы. Такое изменение повысит скорость и эффективность взаимодействия.

В завершении необходимо отметить, что только умелое сочетание процессуальной и организационной деятельности может являться залогом результативного расследования преступлений. Достижение такого сочетания возможно в перспективе только при активном совместном взаимодействии субъектов правоохранительной деятельности и взаимной заинтересованности в результате. Нельзя не отметить важную роль мотивации субъектов, которая осталась без внимания на невысоком уровне на данный момент и негативно влияет на совместное решение задач и взаимную ответственность в ходе следствия. При детальной проработке этого участка работы правоохранительных органов можно достичь роста результативности совместной деятельности следователя в группе с органами дознания. К сожалению, на сегодняшний день можно констатировать, что требования статьи 6 уголовно-процессуального кодекса Российской Федерации в части защиты прав и законных интересов лиц и организаций, потерпевших от преступлений выполняются недостаточно эффективно. Повышение мотивации, эффективности и ответственности органов, осуществляющих уголовное судопроизводство возможно исключительно посредством ведения соответствующей государственной политики в борьбе с преступностью.

\section{ЛИТЕРАТУРА}

1. Кругликов А.П. Сущность и правовые формы взаимодействия органов предварительного следствия и дознания: учебное пособие.- Волгоград, 1985.-C. 21.

2. Дербенев А.П. Взаимодействие следователя и органа дознания при расследовании преступлений: учебное пособие.- М.: Академия МВД СССР, 1983.- С. 6.

3. Зимин Р.В. Содействие органов дознания следователю при производстве предварительного следствия: дис. ... канд. юрид. наук. — М., 2008. — С. 33.

4. Бекетов М.Ю. Актуальные вопросы использования непроцессуальных форм взаимодействия следователя и органов дознания в ходе расследования преступлений // Следователь.— 2000.— № 4.- С. 19-25.

5. Уголовно-процессуальный кодекс Российской Федерации // Собрание законодательства РФ.— 2001.— № 52 (ч. I). — Ст. 4921. 
6. 0 координации деятельности правоохранительных органов по борьбе с преступностью (вместе с Положением о координации деятельности правоохранительных органов по борьбе с преступностью) (ред. от 25.07.2014): указ Президента РФ от 18.04.1996 № 567 // Собрание законодательства РФ. - 1996. — № 17.—Ст. 1958.

7. Об утверждении Инструкции о порядке рассмотрения заявлений, сообщений о преступлениях и иной информации о происшествиях, связанных с безвестным исчезновением лиц (Зарегистрировано в Минюсте России 20.03.2015 № 36499): приказ МВД России № 38, Генпрокуратуры России № 14, СК России № 5 от 16.01.2015 // Российская газета.— 2015. - 30 марта.

8. Об утверждении Инструкции о порядке приема, регистрации и разрешения в территориальных органах Министерства внутренних дел Российской Федерации заявлений и сообщений о преступлениях, об административных правонарушениях, о происшествиях (Зарегистрировано в Минюсте России 06.11.2014 № 34570): приказ МВД России от 29.08.2014 № 736 // Российская газета.— 2014. — 14 нояб.

9. 06 организации предварительного расследования в Следственном комитете Российской Федерации: приказ Следственного комитета РФ от 15.01 .2011 № 2 // СПС «КонсультантПлюс». 2016.

10. Синеокий 0.В. Виды следственных и следственно-оперативных групп: сравнительный анализ // Государство и право.— 1997.— № 1.—C. 60.

11. Колмогоров В. Следствие ищет новые пути борьбы с преступностью // Российская юстиция. — 2000. — № 3.— С. 6.

12. Травкин Е.А. Взаимодействие следователей Следственного комитета Российской Федерации с органами дознания при раскрытии и расследовании преступлений: автореф. дис\. ... канд. юрид. наук.— М., 2011.—С. 8.

13. Карнеева Л.М. Организационные начала расследования преступлений группой следователей // Правоведение. — 1965.— № 3.— C. 91-99.

14. Карнеева Л.М., Галкин И.С. Расследование преступлений группой следователей. - М., 1965.— С. 5.

15. Герасун А.А. Бригадный метод расследования в советском уголовном процессе: дисІ. ... канд. юрид. наук. — М., 1968.— C. 7.

16. Тарасов А.А. Процессуальные и тактико психологические проблемы расследования преступлений группой следователей: дисІ. ... канд. юрид. наук. - Куйбышев, 1990.—- С. 67.

17. Улищенко И.С. Расследование преступлений группой следователей: проблемы правовой регламентации: дис\. ... канд. юрид. наук. - М., 1997.— C. $4-5$.

18. Каплан Л.С. Взаимодействие следователя с органами дознания. - Тюмень, 1999. - С. 67

19. Герасимов И.Ф., Драпкин Л.Я. Основные факторы интенсификации деятельности по раскрытию и расследованию преступлений // Проблемы доказательственной деятельности по уголовным делам: межвузовский сборник. - Красноярск, 1985.— C. 8-15.

20. Хамгоков М.М. Понятие и виды следственной и следственно-оперативной групп // Закон и право.— 2007.— № 12.— С. $67,68$.

21. Цоколов И.А. Процессуальные и криминалистические особенности расследования преступлений следственной и следственно-оперативной группой: дисІ. ... канд. юрид. наук. - М., 2001.— С. 23.

22. Можаева И.П., Степанов В.В. Организационные основы деятельности следователя по раскрытию, расследованию и предупреждению преступлений: монография.-М., 2007.-С. 116,117.

23. Кокурин Г.А. Криминалистические и организационные основы деятельности следственно-оперативных групп по раскрытию и расследованию преступлений: дис\. ... канд. юрид. наук. — Свердловск, 1991.— С. 23.

24. Бажанов С.В. Групповой метод расследования как способ повышения эффективности предварительного следствия: автореф. дисІ. ... канд. юрид. наук.- М., 1990.- С. 12.

25. Улимаев Р.Ю. Следственно-оперативные группы: правовой статус, организация и деятельность: дис. ... канд. юрид. наук. - М., 2002.— С. 32.

26. Савенко Г.М. Следственные группы в уголовном процессе: автореф. дисІ. ... канд. юрид. наук. — М., 2007.— С. 12.

(с) Аристархов Дмитрий Анатольевич ( Dimaris90@mail.ru ).

Журнал «Современная наука: актуальные проблемы теории и практики» 